\title{
Application of the analytic hierarchy process (AHP) to select the best oil spill cleanup method in marine protected areas for calm sea condition
}

\author{
Guidi G. ${ }^{1,}{ }^{*}$, Sliskovic M. ${ }^{2}$, Violante A.C. ${ }^{1}$, and Vukic L. ${ }^{2}$ \\ ${ }^{1}$ Department of Energy Technologies and Renewable Energy Sources, ENEA (Italian National Agency for New Technologies, Energy and \\ Sustainable Economic Development), Via Anguillarese 301, 00123 Rome, Italy \\ ${ }^{2}$ Faculty of Maritime Studies, University of Split, Ruđera Boškovića 37, 21000 Split, Croatia \\ Received: 28/06/2018, Accepted: 09/09/2020, Available online: 11/09/2020 \\ *to whom all correspondence should be addressed: giambattista.guidi@enea.it \\ https://doi.org/10.30955/gnj.002811
}

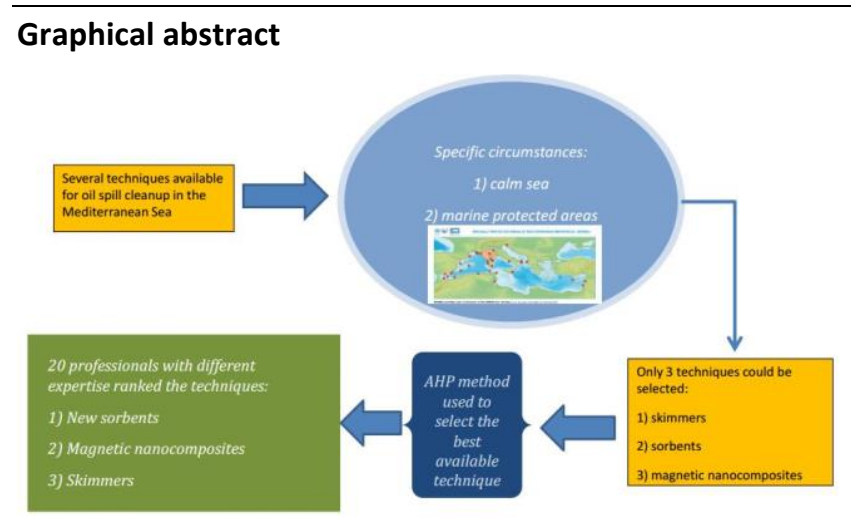

nanocomposites, skimmers, sorbents, analytic hierarchy process.

\section{Introduction}

The number of oil spills, as well as the amount of oil spilled, diminished meaningfully during the last forty-five years. Since 2010, the average number of such events is 1.8 per year, if only the spills greater than $700 \mathrm{t}$ are included (ITOPF, 2018). Unfortunately, they are not yet rare events. In Italy a leak at a refinery, near Genoa, released hundreds of tons of oil in the Polcevera river on April 2016. The oil then spilled into the Mediterranean Sea, one of the world's seas with the highest biodiversity. Given the great population density, substantial fishing activities in the Mediterranean Sea, the creation of marine protected areas has been taken into account (Binet et al., 2015).

Oil spill cleanup is a complex and expensive activity. There are several commonly used techniques available today. The paper suggests criteria for the selection of the best available technique that could be employed in case of oil spills in the Mediterranean Sea under specific circumstances, i.e. calm sea and presence of marine protected areas, in order to prevent pollution. Not all the available techniques could be considered. Only three of them could be selected, as these allow the preservation of natural areas, as well as the protection of threatened species and their habitats. The Analytic Hierarchy Process method has been preferred among the great variety in multi-criteria decision making tools for the selection of the best available technique. This is a widespread decision support tool suitable for the selection of the best alternative solution to a particular problem. Twenty professionals with different expertise evaluated, through pair-wise comparisons, the alternative options to choose in a protected area. The selected emergency cleanup technique must be readily available and operational in a short time. The results give a preference to new sorbents, followed closely by the magnetic nanocomposites technique.

Keywords: Oil spill, best available techniques, Mediterranean sea, marine protected areas, magnetic

According to the most widespread definition, a marine protected area (MPA) is "any area of intertidal or subtidal terrain, together with its overlying water and associated flora, fauna, historical and cultural features, which has been reserved by law or other effective means to protect part or all of the enclosed environment" (Kelleher and Kenchington, 1992, 7).

MPAs are crucial to preserve the biodiversity of the seas and keep producing. They include a variety of sites which can be established and managed by governments, local communities, and nongovernmental organizations (NGOs), private companies and individuals. They have an important role in preserving nature as well as cultural heritage related to it (Lockwood et al., 2006). They can offer opportunities for employment, education, research, and tourism (Secretariat of the Convention on Biological Diversity, 2004).

The Mediterranean Sea is exceptionally sensitive to several damaging effects correlated with maritime transport. It is a particular sensitive ecosystem due to the great volume and frequency of maritime traffic, the long tradition of human use and its peculiar feature of a sea relatively closed and weakly connected with oceans (Abdulla and Linden, 2008). 
Pollution primarily caused by shipping operation is the most significant threat for the Mediterranean today. More than $30 \%$ of the volume of international maritime trade and about $25 \%$ of international maritime transport of oil passes through the Mediterranean waters (Abdulla and Linden, 2008). The consequences of a large oil spill can be catastrophic for the environment, economy, and society. Today, the risk of it is bigger than before because of the presence of numerous offshore facilities in the Mediterranean Sea.

The Protocol concerning Specially Protected Areas and Biological Diversity (IUCN, 1995), ratified in 1995 by the Contracting Parties to the Barcelona Convention, constituted a List of Specially Protected Areas of Mediterranean Importance (SPAMI List) to foster collaboration in the management and conservation of natural areas, as well as in the protection of endangered species and their habitats. As of December 2019, the SPAMI List includes 39 sites (Figure 1), 11 of which are in Italy. Croatia will suggest entries to be added to the SPAMI List just after the undertaken fisheries management reorganization. (UNEP/MAP, 2015).

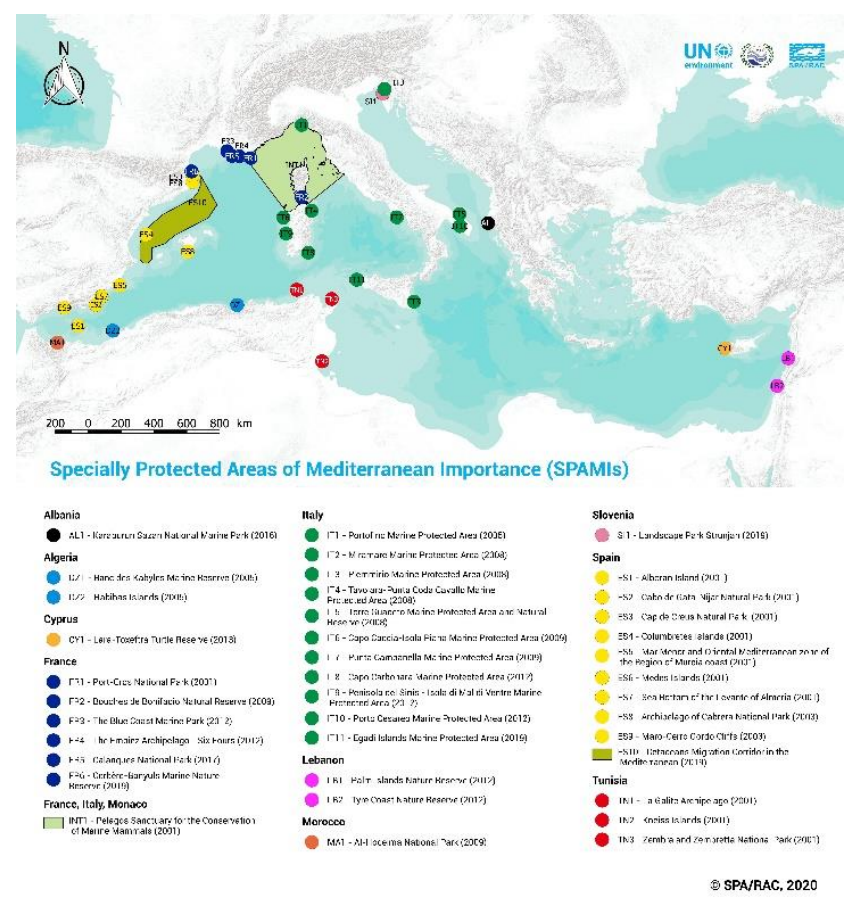

Figure 1. SPAMIs List 2017 (Retrieved from RAC/SPA 2020)

However, the presence of MPAs is not enough to reduce the frequency of accidents and the volume of spilled oil (Dalton and Jin, 2010).

Even a single, large oil spill in a sensitive marine area can bring on environmental damage up to billions of dollars. For the Exxon Valdez oil spill (24 ${ }^{\text {th }}$ March 1989), Exxon had to pay more than $\$ 3.5$ billion which, added to a supplementary compensation of $\$ 5.3$ billion given by an Alaskan jury in 1994 to those affected by the spill, bring the total to $\$ 8.8$ billion (Dalton and Jin, 2010). This value does not differ much from the estimate ( $\$ 6.8$ billion) made by Guidi, Ludovisi, and Mazzarotta (2001), which, appropriately adjusted assuming the cost be affected only by inflation, raises the cost to $\$ 8,4$ billion in 2010 .

The aim of oil spill cleanup is to reduce the total impacts on natural and economic resources. The selection of best available technique (BAT), as well as the correct and timely application, can significantly reduce the size of total damage (ITOPF, 2011). It is crucial to select and deploy a technique as soon as possible.

This paper describes a methodology to select the best available technique in case oil spill events in marine protected areas, based on the Analytic Hierarchy Process (AHP) method, a well-known and effective tool for solving complex decision-making problems.

Current oil spill cleanup methods could be classified into: physical, chemical, thermal and biological (Dave and Ghaly, 2011; Ivshina et al., 2015; Larson, 2010). Physical methods include booms, skimmers and adsorbent materials. Chemical methods are dispersants. In situ-burning is a thermal method and bioremediation is a biological method.

Advanced technology for oil spill cleanup has developed considerably in recent years (Calcagnile et al., 2012; Guidi et al., 2016; Khushrushahi et al., 2013). Two techniques based on magnetic nanocomposites and superabsorbent materials seem to be suitable for application in Specially Protected Areas of Mediterranean Importance (SPAMI).

In presence of SPAMIs, some techniques will be more interesting than others and the ones offering the uppermost degree of resource protection will be consequently selected. Given the urgency of the situation, as the oil spill in a protected area is, the authors took into account the use of a fast and simple decision making method such as Analytic Hierarchy Process (AHP) for the selection of the best compromise solution (Saaty, 1980).

In this paper for the first time a comparison among advanced and classic cleanup technique, as well as between two advanced ones, has been carried out for marine protected areas.

\section{Materials and methods}

Every oil spill is peculiar and various techniques are available for cleanup. When an oil spill occurs, it is of paramount importance to choose the most suitable technique for that specific situation, keeping in mind that each oil spill cleanup technique damages the environment to some extent. Simple and user-friendly criteria will be helpful in making this choice. The selection of the BAT should be done taking into account that the impact of the cleanup technique should be kept to a minimum and, above all, be less significant than the impact of the oil itself. This research takes into account the calm sea condition, because this is a recurrent condition in the Mediterranean Sea, a closed basin. The calm sea condition offers the possibility to consider a greater number of techniques. In rough sea conditions, most techniques are not effective (EPA, 1999).

In calm sea condition, seven cleanup techniques could be effectively employed (Guidi et al., 2009; Guidi et al., 2016): 
- bioremediation;

- booms;

- dispersants;

- in situ burning;

- magnetic nanocomposites;

- skimmers;

- sorbents.

The presence of marine protected area, ecologically sensitive area, restricts the number of employable techniques.

Table 1 shows the techniques that could be employed under the selected circumstances (Guidi et al., 2009).

Table 1. Techniques vs context

\begin{tabular}{|c|c|c|c|}
\hline \multirow{3}{*}{ BAT } & \multicolumn{3}{|c|}{ Context } \\
\hline & \multicolumn{2}{|c|}{ Conditions at sea } & \multirow{2}{*}{$\begin{array}{c}\text { Marine } \\
\text { protected } \\
\text { areas }\end{array}$} \\
\hline & Calm sea & Rough sea & \\
\hline Booms & $x$ & & $x$ \\
\hline Skimmers & $x$ & & $x$ \\
\hline Sorbents & $x$ & & $x$ \\
\hline Dispersants & $x$ & & \\
\hline In-situ burning & $x$ & & \\
\hline \multicolumn{4}{|l|}{ Bioremediation } \\
\hline $\begin{array}{c}\text { Magnetic } \\
\text { nanocomposites }\end{array}$ & $\mathrm{x}$ & $x$ & $x$ \\
\hline
\end{tabular}

Booms were excluded for they are a containment technique rather than a cleanup method (EPA, 1999; Fingas, 2012). They are used to prevent oil from contacting sensitive areas and to facilitate oil removal. They are not a stand-alone technique, whereas they have to be necessarily used together with other techniques, such as skimmers. Aggressive techniques, for instance dispersants and in situ burning, could not be employed in presence of particularly sensitive areas such as MPAs. Dispersants are toxic to water fauna and flora (Al-Majed et al., 2012). Even if the dispersants available today are less toxic and more effective than the ones previously used (Lessard and Demarco, 2000), they can bring about potential harm to marine ecosystem (Dave and Ghaly, 2011). Even calm sea conditions, they are not suitable because of the lack of enough energy to mix dispersants and oil (Al-Majed et al., 2012). As far as concerns in situ burning, it is not a

Table 2. Main characteristics of selected BATs

\begin{tabular}{ccccc}
\hline $\begin{array}{c}\text { Best available } \\
\text { technique }\end{array}$ & Oil absorption capacity & Maintenance required & Cost & $\begin{array}{c}\text { Damage to marine } \\
\text { environment }\end{array}$ \\
\hline Skimmers & Very high & Yes & High & No \\
\hline New sorbents & Very high & No & Low & Possible \\
\hline $\begin{array}{c}\text { Magnetic } \\
\text { nanocomposites }\end{array}$ & High & No & Moderate & Possible \\
\hline
\end{tabular}

suggested technique in this case also because aquatic flora and fauna may feel the effect of burning, along with longterm changes in water plants and animals (Dave and Ghaly, 2011). Albeit bioremediation could be a useful technique, it was excluded because it has to be used sparingly to control oxygen reduction (U.S. Congress, Office of Technology Assessment, 1991) which can be a notable factor in the inhibition of oil biodegradation (Lee and Levy, 1991). Actually, if an excessive quantity of bacteria is added, they will make use of all the oxygen in the area, to the detriment of the other organisms. On the other hand, bioremediation is a process that slowly removes oil from the environment and can last for months and years (Atlas and Hazen, 2011; Swannell et al., 1996). Besides, bioremediation does not introduce native species to the environment. This therefore causes contention between the endemic and foreign microbes (Radermacher, 2005; Venosa et al., 1996).

In the light of these considerations the authors decide to consider the following techniques:

- skimmers;

- sorbents;

- magnetic nanocomposites.

Advanced oleophilic skimmers have been developed with a recovery efficiency of no less than $70 \%$. A tailoring of the oleophilic skimmers surface geometry and a proper choice of the recovery surface material could further enhance their recovery rate (Broje and Keller, 2006; Broje and Keller, 2007).

Many sorbent materials are limited in oil absorption potential. On the contrary, they have good water absorption properties. Progress in polyolefin chemistry made it possible to discover the polyolefin-based superabsorbent polymers (oil-SAP) showing important features in the oil spill cleanup process (Yuan and Chung, 2012) such as: great oil absorption capability (up to 40 times its weight), no water absorption and costeffectiveness. Several works described augmented oil absorption capacity and oil-water selectivity of alteration of their surface properties, at times making them into magnetic nanocomposite materials (Calcagnile et al., 2012; Pinto et al., 2016). polyurethane (PU) foams with the aid of chemical
A variety of magnetic nanocomposites materials and techniques are now available for oil spill cleanup (Calcagnile et al., 2012; Khushrushahi et al., 2013). Nicolaides et al. (1998) proposed a magnetic separation technique, based on a nanocomposite magnetic eco- friendly material, with oleophilic and porous characteristics, with an oil absorption capacity that can reach up to 9 times its weight. Other works proposed coreshell $\mathrm{Fe}_{2} \mathrm{O}_{3} @ \mathrm{C}$ water-repellent and superoleophilic nanoparticles (Zhu et al., 2010), $\mathrm{Fe}_{3} \mathrm{O}_{4} / \mathrm{PS}$ nanocomposites 
(Yu et al., 2015), magnetic nanocomposite of collagen and superparamagnetic iron oxide nanoparticles (Thanikaivelan et al., 2012). There are some concerns that nanoparticles could be toxic to people and could damage marine environment. Nevertheless, subsequent real-scale experiments and analysis have to be performed in order to draw trustworthy conclusions (McCall and Pennings, 2012).

As for the costs of these techniques, the production cost of new oil-SAP material could be lower than $4.4 \$ / \mathrm{kg}$ in largescale production. Nineteen litres of spilled oil can be recovered using $0.45 \mathrm{~kg}$ of oil-SAP, treating the spill as a resource, not as a waste (Yuan and Chung, 2012). According to these data, the authors estimated the cost of the material to be around 119 US $\$ / t$. This value, even though without logistics, is significantly lower than the ones associated with mechanical methods $(13,774.58$ US $\$ / t)$ and magnetic nanocomposites (1,000-2,250 US $\$ / t$ ) (Guidi et al., 2016). The cost of these latter materials is expected to fall, reaching the same order of magnitude as the cost of sorbents (Mahajan, 2011).

Table 2 summarizes the key features of the techniques, in the light of the above considerations.

Fundamentally, this work aims at selecting the best available technique under definite circumstances:

- calm sea;

- $\quad$ presence of marine protected areas (SPAMIs).

The multi-criteria decision making methods are able to prioritize and rank the available techniques under the above mentioned context. Application of the AHP method is part of the authors' long-term project of testing decisionmaking procedures in various circumstances of oil spills (Guidi et al., 2009; Guidi et al, 2016). AHP has been originally chosen because it is simple, immediate and quick. AHP permits to calculate relative weights of the evaluation criteria, while in other methods, such as ELECTRE, PROMETEE and TOPSIS, weights are usually fixed by each decision-maker. Finally, the other methods are often based on slow and more complicated procedures (Zafirakou et al., 2018).

A group of 20 professionals with different expertise (mainly maritime studies (5) and marine environmental science (5) but also applied physics (1), biology (2), chemistry (2), different engineering specialties (3), economics (1), geology (1)) evaluated three different techniques using AHP method (Saaty, 2008). The professionals were selected among academic staff of University of Split - Faculty of Maritime Studies and researchers of ENEA, who had previously worked with MCDM methods and oil spills.

AHP is one of the most used and successful methods for prioritizing and ranking alternatives. The method is valuable when complex problems, affecting human perceptions and judgements, must be solved. It is very useful when elements of the decision are difficult to quantify or compare or when different specializations prevent people from communicating effectively in a work team.
There are three steps in the AHP method: pairwise comparisons, calculation of relative weights and assessment of consistency of pairwise judgement.

The professionals were informed about the aim of the investigation (to select the best available technique for oil spill cleanup in the Mediterranean Sea in calm sea conditions and in presence of marine protected areas) together with the key features of the techniques (Table 2). By means of the known Saaty's scale (Saaty, 2008) showed in Table 3, they compared pair-wise each option to the others using numbers to express how much a technique outdoes another as regards the assigned criterion: the presence of marine protected areas.

Table 3. Saaty's scale

\begin{tabular}{cc}
\hline Intensity of importance & Definition \\
\hline 1 & Equal importance \\
\hline 3 & Moderate importance \\
\hline 5 & Strong importance \\
\hline 7 & Very strong importance \\
\hline 9 & Extreme importance \\
\hline $2,4,6,8$ & Intermediate values \\
\hline
\end{tabular}

Table 4 shows the matrix the professionals were asked to fill in. This matrix was sent to their e-mail address.

Table 4. Comparison matrix

\begin{tabular}{cccc}
\hline & Skimmers & $\begin{array}{c}\text { New } \\
\text { sorbents }\end{array}$ & $\begin{array}{c}\text { Magnetic } \\
\text { nanocomposites }\end{array}$ \\
\hline Skimmers & 1 & & \\
\hline New sorbents & & 1 & \\
\hline $\begin{array}{c}\text { Magnetic } \\
\text { nanocomposites }\end{array}$ & & 1 \\
\hline
\end{tabular}

A judgemental matrix was sent back by each professional with their pair-wise comparison, according to their best knowledge, and it was used to compute the priorities.

\section{Results and discussion}

The priorities stated by the professionals, after the pairwise comparison, have been then combined by means of the geometric mean. The results are shown in Tables $5 \mathrm{~A}$ and $5 \mathrm{~B}$. Each weight value is obtained by dividing the geometric mean of each line by the local sum of the geometric means. For istance, the weight referred to skimmers $(0.136)$ is obtained by dividing the corresponding geometric mean $(0.464)$ by 3.412 . $\mathrm{K}$ eigenvalues are inferred by multiplying each weight calculated for each $\mathrm{BAT}$, by the matching total. For instance, the second $\mathrm{K}$ eigenvalue (1.038) is obtained by multiplying the weight 0.471 by 2.204 .

When the $\mathrm{K}$ eigenvalues are known, the consistency index (Cl) is given by formula (1):

$$
C I=\frac{K_{t o t}-n}{n-1}
$$


Table 5A. Comparison matrix

\begin{tabular}{cccc}
\hline & Skimmers & $\begin{array}{c}\text { New } \\
\text { sorbents }\end{array}$ & $\begin{array}{c}\text { Magnetic } \\
\text { nanocomposites }\end{array}$ \\
\hline Skimmers & 1 & 0.253 & 0.395 \\
\hline New sorbents & 3.948 & 1 & 1.052 \\
\hline $\begin{array}{c}\text { Magnetic } \\
\text { nanocomposites }\end{array}$ & 2.531 & 0.950 & 1 \\
\hline Total & 7.479 & 2.204 & 2.447 \\
\hline
\end{tabular}

$\ln (1) n$ is the number of components. The consistency ratio (CR) is the ratio of the consistency index to the random consistency index (RI). RI stands for the consistency of a randomly generated pair-wise comparison matrix. It is an average random consistency index, obtained from a sample of 500 casually generated matrices hinged on AHP scale. In our case (three components), RI has 0.58 value (Saaty, 1980).

It is worth noting (Table 6) that the consistency ratio (0.01) is much lower than 0.1 , so the pair-wise comparison matrix should be regarded as consistent enough. The expert group gave the highest weight to the new sorbents $(0.471)$, followed closely by magnetic nanocomposites (0.393), while skimmers were judged to be the less suitable technique (0.136).

Table 6. Index values

\begin{tabular}{cccc}
\hline $\begin{array}{c}\text { No. of } \\
\text { components }\end{array}$ & $\begin{array}{c}\text { Consistency } \\
\text { index }\end{array}$ & RI & CR \\
\hline 3 & 0.009 & 0.58 & 0.01 \\
\hline
\end{tabular}

The results could suggest the application of the technique over all the protected areas in the world where there are interests and possibilities to protect the sea. As an example, the result could be easily extended to the case of submerged archaeological sites, where techniques such as dispersants or in situ burning should be avoided (Guidi et al., 2009). Submerged archaeological sites are in the Mediterranean Sea (for example Baiae, Bay of Naples) but also in other seas, such as the North Sea (for example Area 240, Doggerland), Caribbean Sea (for example Port Royal, Kingston Harbour), Bay of Bengal (for example The Shore Temple, Mahabalipuram), the English Channel (for example Bouldnor Cliff, Isle of Wight) and so on. In case of different geographic and climate conditions in world's oceans and seas, it becomes necessary to carry out analogous research, for example using different criteria.

\section{Conclusions and further developments}

AHP method underlined the preference given by the professionals to new sorbents, followed by magnetic nanocomposites, while skimmers were judged to be the less appropriate techniques under the above-mentioned circumstances. Forasmuch as the consistency ratio is 0.01 (decidedly smaller than 0.1 ) the pair-wise comparison matrix can be deemed as definitely consistent. This work shows the results of a research activity aiming at offering an appropriate and user-friendly tool to competent authorities for oil spill cleanup.

In a further development, the AHP method could be applied for the selection of the best available technique under different circumstances Thus, the competent authorities could have an easy-to-use tool that will allow them to cope with oil spill under different circumstances, always relying on the best available solution. A possible future work could also foresee the integration of AHP with TOPSIS method. The qualitative data in Table 2 could be converted into quantitative scores, the weights calculated using AHP and then applying TOPSIS method in order to confirm or not the preference given by the experts to new sorbents.

\section{Acknowledgements}

The authors would like to thank all the professionals with different specializations who evaluated the different cleanup techniques. This research did not receive any specific grant from funding agencies in the public, commercial, or not-for-profit sector.

\section{References}

Abdulla A. and Linden O. (2008), Maritime traffic effects on biodiversity in the Mediterranean Sea. Volume 1 - Review of impacts, priority areas and mitigation measures, IUCN Centre for Mediterranean Cooperation, Malaga, Spain.

Al-Majed A.A., Adebayo A.R. and Hossain M.E. (2012), A sustainable approach to controlling oil spills, Journal of Environmental Management, 113, 213-227. doi:10.1016/j.jenvman.2012.07.034.

Atlas R.M., and Hazen T.C. (2011), Oil biodegradation and bioremediation: a tale of the two worst spills in U.S. history, Environmental Science \& Technology, 45, 6709-6715. doi:10.1021/es2013227.

Binet T., Diazabakana A. and Hernandez S. (2015), Sustainable financing of Marine Protected Areas in the Mediterranean: a financial analysis. Vertigo Lab, MedPAN, RAC/SPA, WWF Mediterranean.

Broje V. and Keller A.A. (2006), Improved mechanical oil spill recovery using an optimized geometry for the skimmer surface, Environmental Science \& Technology, 40(24), 79147918

Broje V., and Keller A.A. (2007), Effect of operational parameters on the recovery rate of an oleophilic drum skimmer, Journal of Hazardous Materials, 148, 136-143

Calcagnile P., Fragouli D., Bayer I.S., Anyfantis G.C., Martiradonna L., Cossoli P.D., Cingolani R. and Athanassiou A. (2012), Magnetically driven floating foams for the removal of oil contaminants from water, ACS Nano, 6(6), 5413-5419. doi:10.1021/nn3012948.

Dalton T. and Jin D. (2010), Extent and frequency of vessel oil spills in US marine protected areas, Marine Pollution Bulletin, 60(11), 1939-1945. doi:10.1016/j.marpolbul.2010.07.036.

Dave D. and Ghaly A.E. (2011), Remediation technologies for marine oil spills: a critical review and comparative analysis, American Journal of Environmental Science, 7 (5), 423-440. doi:10.3844/ajessp.2011.423.440.

Environmental Protection Agency (EPA) Office of Emergency and Remedial Response (1999), Mechanical containment and recovery of oil following a spill. In: Understanding oil spills and oil spill response. United States Office of Emergency Environmental Protection and Remedial Agency Response. https://nepis.epa.gov/Exe/ZyPDF.cgi/10001XNZ.PDF?Dockey $=10001$ XNZ.PDF

Fingas M. (2012), The basics of oil spill cleanup, Third Edition, CRC Press, Boca Raton. 
Guidi G., Gugliermetti F. and Violante A.C. (2009), Proposed criteria to select best available techniques (BATs) for oil spill response, Chemical Engineering Transactions, 17, 367-372. doi:10.3303/CET0917062.

Guidi G., Ludovisi G. and Mazzarotta B. (2001), Methodological approach for the evaluation, in economic terms, of the risk arising from industrial plants subject to Council Directive 96/82/CE (Seveso II). In: Safety and Reliability Towards a Safer World, Zio E., Demichela M. and Piccinini N. (eds.), Politecnico di Torino, Torino, 521-528

Guidi G., Sliskovic M., Violante A.C. and Vukic L. (2016), Best available techniques (BATs) for oil spill response in the Mediterranean Sea: calm sea and presence of economic activities, Environmental Science Pollution, 23, 1944-1953. doi: 10.1007/s11356-015-5543-y.

International Tanker Owner Pollution Federation Limited (2011), Effects of oil pollution on the environment. Documents and Guides category. http://www.itopf.com/knowledgeresources/documents-guides/document/tip-13-effects-ofoil-pollution-on-the-marine-environment/ (accessed October 18, 2016).

International Tanker Owner Pollution Federation Limited (2018), Oil tanker spill statistics 2017. https://www.itopf.org/file admin/data/Photos/Statistics/Oil_Spill_Stats_2017_web.pdf (accessed December 20, 2018)

IUCN (1995), Protocol concerning specially protected areas and biological diversity in the Mediterranean. SPA \& Biodiversity Protocol. Barcelona. http://extwprlegs1.fao.org/docs/pdf/ mul38152.pdf. (accessed October 10, 2016).

Ivshina I.B., Kuyukina M.S, Krivoruchko A.V., Elkin A.A., Makarov S.O., Cunningham C.J., Peshkur T.A., Atlas R.M. and Philp J.C. (2015), Oil spill problems and sustainable response through new technologies, Environmental Science Processes \& Impact, 17, 1201-1219.

Kelleher G. and Kenchington R. (1992), Guidelines for Establishing Marine Protected Areas. A Marine Conservation and Development Report, IUCN, Gland, Switzerland.

Khushrushahi S., Zahn M. and Hatton T.A. (2013), Magnetic separation method for oil spill cleanup, Magnetohydrodynamics, 49(3), 546-551.

Larson H. (2010), Responding to oil spill disasters: The regulations that govern their response. http://www.wiseintern.org/journal/2010/hattielarsonwise2010.pdf (accessed December 16, 2018).

Lee K. and Levy E.M. (1991), Bioremediation: waxy crude oils stranded on low-energy shorelines. In: Proceedings of the 1991 Oil Spill Conference (Prevention, Behaviour, Control, Cleanup), American Petroleum Institute, Washington DC, pp. 541-547.

Lessard R.R., and De Marco G. (2000), The significance of oil spill dispersants, Spill Science and Technology Bulletin, 6(1), 59-68. doi: 10.1016/S1353-2561(99)00061-4.

Lockwood M., Worboys G.L. and Kothari A. (2006), Managing protected areas: A global guide. Earthscan, London.

Mahajan Y.R. (2011), Nanotechnology-based solutions for oil spills, Nanotechnology Insights, 2(1), 1-19.

McCall B.D. and Pennings S.C. (2012), Disturbance and Recovery of Salt Marsh Arthropod Communities following BP Deepwater Horizon Oil Spill. PLOS ONE, 7(3), e32735. doi:10.1371/journal.pone.0032735.
Nicolaides G.K., Skountzo P., Atanassova Y. and Koutroumbas K. (1998), CLEANMAG ${ }^{\circ}$ : The magnetic cleanup of waterborne oil spills - A new approach in the battle of oil spill cleanups. In: EUROMAT'98, Conference of the Portuguese-European Material Society on Materials in Oceanic Environment, Lisbon, pp. 709-717.

Pinto J., Athanassiou A. and Fragouli D. (2016), Effect of the porous structure of polymer foams on the remediation of oil spills, Journal of Physics D: Applied Physics, 49(14), 145601. doi:10.1088/0022-3727/49/14/145601.

RAC/SPA (2020), SPAMIs. Regional Activity Center for Specially Protected Areas. http://www.rac-spa.org/spami (accessed 8 July 2020).

Radermacher M. (2005), Bioremediation of marine oil spills. Engineering Technology Support. Iowa State University. http://home.engineering.iastate.edu/ tge/ce421-521/mattr.pdf. (accessed November 27, 2017).

Saaty T.L. (1980), The analytic hierarchy process: planning, priority setting, resource allocation. McGraw-Hill Inc., New York.

Saaty T.L. (2008), Decision making with the analytic hierarchy process, International Journal of Services Sciences, 1(1), 8398.

Secretariat of the Convention on Biological Diversity (2004), Programme of Work on Protected Areas (CBD Programmes of Work), Secretariat of the Convention on Biological Diversity, Montreal.

Swannell R.P.J., Lee K. and McDonagh M. (1996), Field evaluation of marine oil spill bioremediation, Microbiological Reviews, 60(2), 342-365.

Thanikaivelan P., Narayanan N.T., Pradhan B. and Ajayan P.M. (2012), Collagen-based magnetic nanocomposites for oil removal application, Scientific Reports, 2, 230. doi: 10.1038/srep00230.

UNEP/MAP (2015), Progress Report of the "Project on Mapping of key marine habitats in the Mediterranean and promoting their conservation through the establishment of Specially Protected Areas of Mediterranean Importance (SPAMIS)" (MedKeyHabitats Project), United Nations Environment Programme (UNEP), Tunis. http://racspa.org/nfp12/documents/information/wg.408_inf6_eng.pd $f$ (accessed October 5, 2016).

U.S. Congress - Office of Technology Assessment (1991), Bioremediation for Marine Oil Spills - Background Paper. OTABP-O-70, U.S. Government Printing Office, Washington DC. https://www.princeton.edu/ ota/disk1/1991/9109/9109.PD F (accessed November 28, 2017).

Venosa A.D., Suidan M.T., Wrenn B.A., Strohmeier K.L., Haines J.R., Eberhart B.L., King D. and Holder E. (1996), Bioremediation of an experimental oil spill on the shoreline of Delaware Bay, Environmental Science \& Technology, 30(5), 1764-1775. doi: 10.1021/es950754r.

Yu L., Hao G., Gu J., Zhou S., Zhang N. and Jiang W. (2015), $\mathrm{Fe}_{3} \mathrm{O}_{4} / \mathrm{PS}$ magnetic nanoparticles: synthesis, characterization and their application as sorbents of oil from wastewater, Journal of Magnetism and Magnetic Materials, 394, 14-21. doi: 10.1016/j.jmmm.2015.06.045.

Yuan X. and Chung M.T.C. (2012), Novel solution to oil spill recovery: Using Thermodegradable Polyolefin Oil Superabsorbent Polymer (Oil-SAP), Energy \& Fuels, 26, 4896-4902. doi:10.1021/ef300388h. 
Zafirakou A., Themeli S., Tsami E. and Aretoulis G. (2018), Multicriteria analysis of different approaches to protect the marine and coastal environment from oil spills, Journal of Marine Science and Engineering, 6(4), 125. doi: 10.3390/jmse6040125.

Zhu Q., Tao F. and Pan Q. (2010), Fast and selective removal of oils from water surface via highly hydrophobic core-shell $\mathrm{Fe}_{2} \mathrm{O}_{3} @ \mathrm{C}$ nanoparticles under magnetic field, ACS Applied Materials \& Interfaces, 2(11), 3141-3146. doi: 10.1021/am1006194. 